\title{
The effect of plant polyphenols on the antioxidant defence system of weaned piglets subjected to an Escherichia coli challenge
}

\author{
X.R. Jiang ${ }^{1,5}$, H.J. Zhang ${ }^{2,5}$, G. Mantovani', G.L. Alborali'3, J.M. Caputo', G. Savoini', V. Dell'Orto' \\ and V. Bontempo ${ }^{1,4}$ \\ ${ }^{1}$ Università degli Studi di Milano, Department of Health, Animal Science and Food Safety, Department of Health, Animal Science \\ and Food Safety, Via Celoria 10, 20133 Milan, Italy \\ ${ }^{2}$ Chinese Academy of Agricultural Sciences, Key Laboratory of Feed Biotechnology of the Ministry of Agriculture \\ Zhongguancun Nandajie 12, 100081 Beijing, China \\ ${ }^{3}$ Lombardy and Emilia Romagna Experimental Zootechnic Institute \\ Via Bianchi 9, 25124 Brescia, Italy
}

KEY WORDS: antioxidant capacity,

E. coli challenge, plant polyphenols, piglets

Received: 24 July 2014

Revised: 25 September 2014

Accepted: 28 November 2014

${ }^{4}$ Corresponding author:

e-mail: valentino.bontempo@unimi.it

${ }^{5}$ X.R. Jiang and H.J. Zhang contributed equally

\begin{abstract}
The goal of this study was to evaluate the effect of an optimized plant polyphenol (PP) mixture consisting of polyphenols extracted from apples, grape seeds, green teas and olive leaves on the systemic antioxidant capacity in piglets orally challenged with Escherichia coli (E. coli). A total of 24 piglets were weaned at 28 days and allocated to 4 groups for a 42-d experiment with a $2 \times 2$ factorial design comparing different dietary treatments [a basal diet without (CTR) or with $0.1 \%$ of the optimized PP mixture (PP)] and oral E. coli challenges on days 21 and 25 (saline or $E$. coli). On days 25,27 and 34 of the trial, one piglet from each pen was selected for blood sampling. The E. coli challenge decreased the gain-to-feed ratio (G:F) from day 21 to day 42 $(P<0.10)$, reduced plasma superoxide anion (SAIC) and hydroxyl radical (HRIC) inhibiting capacities, and increased the plasma ceruloplasmin content on day $27(P<0.10)$. PP supplementation increased the G:F ratio from day 21 to day $42(P<0.10)$. Compared with the CTR diet, PP supplementation increased plasma GSH-Px activity on day 25 and plasma T-AOC activity on day 27 $(P<0.10)$, and dietary PP increased plasma SAIC on day 27 and plasma HRIC on day $34(P<0.10)$. These results suggest that PP supplementation may improve the antioxidant status of post-weaning piglets and counteract some of the negative effects that occur when piglets are challenged with $E$. coli.
\end{abstract}

\section{Introduction}

Phytogenic feed additives are plant-derived products used in animal feeding to improve the performance of agricultural livestock (Windisch et al., 2008) possible modes of action, and aspects of application of phytogenic products as feed additives for pigs and poultry. Phytogenic feed additives comprise a wide variety of herbs, spices and products derived thereof, and are mainly essential oils.
The assumption that phytogenic compounds might improve the palatability of feed has not yet been confirmed by choice-feeding studies. Although numerous studies have demonstrated antioxidative and antimicrobial efficacy in vitro, respective experimental in vivo evidence is still quite limited.

The same applies to the supposition that phytogenic compounds may specifically enhance activities of digestive enzymes and nutrient absorption. Nevertheless, a limited number of experimental 
comparisons of phytogenic feed additives with antibiotics and organic acids have suggested similar effects on the gut, such as reduced bacterial colony counts, fewer fermentation products (including ammonia and biogenic amines). Polyphenols are naturally bioactive compounds found in many foods, including fruits, wine and tea, as well as wood waste, such as larch bark (Heim et al., 2002). Polyphenols containing plant extracts are widely used as additives in various livestock feed and food products, based on their presumed positive effects, which are generally attributed to their anti-oxidative ( $\mathrm{Lu}$ et al., 2011) and anti-bacterial properties (Gordon and Wareham, 2010). Furthermore, plant polyphenols were reported to inactivate enterotoxin in vitro (Morinaga et al., 2005), and flavonoids and related polyphenolic compounds have significant anti-inflammatory activity (González et al., 2011). In addition, polyphenols from grape seeds were reported to be responsible for preventing oxidative damage to cellular DNA in vitro (Fan and Lou, 2004).

In pigs, enterotoxigenic Escherichia coli (ETEC) infections occurring immediately after birth (neonatal diarrhoea) and after weaning (postweaning diarrhoea) are responsible for significant financial losses due to diarrhoea, growth retardation and mortality (Verdonck et al., 2002). Economically, the pork industry is by far the hardest hit, due to increased rates of mortality and morbidity, and decreased growth rate of newborn and early weaned piglets (Fairbrother et al., 2005). The overproduction of reactive-oxygen species and reactive-nitrogen species may result in oxidative stress (Valko et al., 2007) and changes in the antioxidant defence systems (Han et al., 2009, 2011). In farm animals, several pathological disorders, including those relevant to health and animal production, may be linked to oxidative stress (Lykkesfeldt and Svendsen, 2007).

The purpose of this study was to determine the effect of a prepared PP complex, optimized on the basis of in vitro results (Zhang et al., 2014), on the antioxidant defence systems of post-weaning piglets in the presence of an experimentally induced $E$. coli challenge. In order to strengthen the challenge effect, injections of $E$. coli were delivered twice, on days 21 and 25 of the trial.

\section{Material and methods}

\section{Animals, treatments, and $E$. coli challenge}

The experimental protocol was reviewed and approved by the Animal Care and Use Committee of the University of Milan.
The experiment was carried out at the facility for Animal Production Research and Teaching Centre of the Polo Veterinario, Università degli Studi di Milano, University of Milan (Italy). Twenty-four weaned crossbred barrow piglets $[(\mathrm{L} \times \mathrm{LW}) \times$ Penerland, 28 days old, $7.73 \pm 0.97$ body weight $(\mathrm{BW})]$, homogeneous for weight, age, sex and litter origin, were assigned to 4 treatment groups ( 3 replicates with 2 piglets per treatment) within 12 pens. A pen was the experimental unit. Piglets were housed in one environmentally regulated room in an isolated stable, with 2 piglets per pen kept on raised weaner decks equipped with a mesh floor. The pig barn was maintained at temperatures between $25^{\circ} \mathrm{C}$ and $28^{\circ} \mathrm{C}$, with a 12 -h light/dark cycle.

The piglets were raised for 42 days in 4 different groups, with a $2 \times 2$ factorial design for comparing different treatments [a basal diet without (CTR) or with an optimized plant polyphenol (PP) mixture $(0.1 \%$ of diet $)]$ and oral $E$. coli challenges (saline or E. coli). The basal feed (Table 1) was formulated according to $\mathrm{NRC}$ requirements (2012). All feed was in mash form. Complex formulations of 4 polyphenols: apple polyphenol and grape seed polyphenol (Tianjin Jianfeng Natural Product R\&D Co., Ltd., Tianjin, China), green tea polyphenol (Taiyo Green Power Co., Ltd., Wuxi, China) and olive leaf polyphenol (Ningbo SinoTaipio Herbal Science Co., Ltd., Ningbo, China)], combined with silicon dioxide as a carrier, were tested using a uniform design at the Key Laboratory of Feed Biotechnology within the Ministry of Agriculture of the Chinese Academy of Agricultural Sciences (Beijing, China). The optimal PP mixture was obtained based on in vitro antioxidant capacity and inhibition of bacterial growth. In accordance with the preliminary in vitro test described previously (Zhang et al., 2014), the optimal PP mixture consisted of $16.5 \%$ apple polyphenol, $27.5 \%$ grape seed polyphenol, $30 \%$ green tea polyphenol, $2.5 \%$ olive leaf polyphenol and $23.5 \%$ carrier (silicon dioxide).

On days 21 and 25 of the trial, half of the piglets in each diet treatment were orally inoculated with $4 \mathrm{ml}$ of a solution containing $10^{9} \mathrm{CFU}$ of E. coli, or an equal amount of physiological saline solution. The challenge strain used in this experiment was E. coli O139:K82 LT isolated from a clinical case with PWD, obtained from Lombardy and Emilia Romagna Experimental Zootechnic Institute (Brescia, Italy). A 1-way traffic path was implemented to prevent non-challenged pigs from coming into contact with challenged pigs. 
Table 1. Composition and calculated nutrient content of the basal diet, $\%$

\begin{tabular}{|c|c|c|}
\hline Indices & $\begin{array}{l}\text { Prestarter } \\
\text { day } 0-14 \\
\text { of the trial }\end{array}$ & $\begin{array}{l}\text { Starter } \\
\text { day } 14-42 \\
\text { of the trial }\end{array}$ \\
\hline \multicolumn{3}{|l|}{ Ingredients, $\%$} \\
\hline maize meal & 31.3 & 30.4 \\
\hline biscuits flaked & 15 & 13.8 \\
\hline maize flaked & 13 & - \\
\hline barley & 8 & 11.9 \\
\hline dried whey & 7.5 & 5 \\
\hline soyabean meal (44\% CP) & 6.5 & 6.6 \\
\hline Probiolat $^{1}$ & 5 & 5 \\
\hline herring meal & 5 & 5 \\
\hline soya protein conc. (Soycomil) & 5 & 3.5 \\
\hline whey solubles & 5 & 2.5 \\
\hline wheat middlings & 4 & 12 \\
\hline calcium carbonate & 1 & 1.15 \\
\hline dicalcium phosphate & 1 & 0.85 \\
\hline L-lysine $\mathrm{HCl} 78$ & 0.7 & 0.4 \\
\hline L-threonine & 0.6 & 0.15 \\
\hline soya oil & 0.5 & 1 \\
\hline mineral-vitamin mixture ${ }^{2}$ & 0.5 & 0.5 \\
\hline DL-methionine & 0.25 & 0.1 \\
\hline $\mathrm{NaCl}$ & 0.15 & 0.15 \\
\hline \multicolumn{3}{|l|}{ Calculated nutrient composition, \% } \\
\hline crude protein & 18.82 & 18.13 \\
\hline crude fibre & 2.82 & 3.57 \\
\hline ether extract & 5.62 & 6.03 \\
\hline ash & 7.03 & 7.02 \\
\hline lysine & 1.47 & 1.21 \\
\hline methionine & 0.58 & 0.43 \\
\hline met+cys & 0.81 & 0.67 \\
\hline threonine & 1.26 & 0.81 \\
\hline tryptophane & 0.18 & 0.19 \\
\hline $\mathrm{Ca}$ & 1.04 & 1.05 \\
\hline available $P$ & 0.45 & 0.44 \\
\hline $\mathrm{ME}, \mathrm{kcal} \cdot \mathrm{kg}^{-1}$ & 3250 & 3150 \\
\hline
\end{tabular}

${ }^{1}$ Probiolat: whey concentrate protein + soyabean concentrate protein; ${ }^{2}$ inclusion per kg in the diet: IU: vit. $A_{3} 600000$, vit. $D_{3} 360000$; mg: vit. $E$ (dl-a-tocopherol acetate) 24000 , thiamine (vit. $B_{1}$ ) 800, pyridoxine (vit. $\left.B_{6}\right) 1000$, vit. $K_{3} 400$, niacin (nicotinic acid) 50, pantothenic acid 3600 , folic acid 400, choline $90000, \mathrm{Mn}(\mathrm{MnO}) 8000$, Zn (ZnO) $29000, \mathrm{Fe}\left(\mathrm{FeSO}_{4} \cdot \mathrm{H}_{2} \mathrm{O}\right) 46000, \mathrm{Cu}\left(\mathrm{CuSO}_{4} \cdot 5 \mathrm{H}_{2} \mathrm{O}\right) 30000, \mathrm{Co}$ $\left(\mathrm{CoSO}_{4} \cdot 7 \mathrm{H}_{2} \mathrm{O}\right) 200, \mathrm{I}(\mathrm{KI}) 300, \mathrm{Se}\left(\mathrm{Na}_{2} \mathrm{SeO}_{3}\right) 70 ; \mu \mathrm{g}$ : riboflavin (vit. $\mathrm{B}_{2}$ ) 1200 , cyanocobalamin (vit. $\mathrm{B}_{12}$ ) 8000 , biotin 60000

\section{Experimental observations and measurements}

All piglets were individually weighed on days 0 , 21 and 42 of the trial. The average daily gain (ADG), average daily feed intake (ADFI) and gain-to-feed ratio $(\mathrm{G}: \mathrm{F})$ values were calculated for each pen. On days 25 (before the second E. coli inoculation), 27 and 34 of the trial, a blood sample was taken from one piglet in each pen. Plasma was collected following centrifugation $\left(1800 \mathrm{~g}\right.$ at $4^{\circ} \mathrm{C}$ for $\left.10 \mathrm{~min}\right)$ and stored at $-20^{\circ} \mathrm{C}$ in preparation for analysis.

The plasma parameters were determined using assay kits according to the manufacturer's instructions (Nanjing Jiancheng Bioengineering Institute, Nanjing, China). Superoxide dismutase (SOD) activity was detected by monitoring the inhibition of nitro blue tetrazolium reduction. Glutathione peroxidase (GSH-Px) activity was measured with 5,50 -dithiobis- $p$-nitrobenzoic acid, and the change in absorbance at $412 \mathrm{~nm}$ was recorded. The malondialdehyde (MDA) concentration was analysed with 2-thiobarbituric acid, and the change in absorbance was read at a wavelength of $532 \mathrm{~nm}$. Catalase (CAT) activity was determined using Aebi's method (1984), in which the initial rate of hydrogen peroxide decomposition is determined. Total antioxidant capacity (T-AOC) was measured by a ferric reducing/antioxidant power assay (Benzie and Strain, 1996). The superoxide anion inhibiting capacity (SAIC) and hydroxyl radical inhibiting capacity (HRIC) of plasma were analysed using assay kits according to the manufacturer's instructions (Nanjing Jiancheng Bioengineering Institute, Nanjing, China). SAIC was estimated using the cytochrome $c$ reduction method by capturing the superoxide anion produced from a xanthine oxidase-hypoxanthine (or xanthine) reaction at $\mathrm{pH} 7.4$ and a wavelength of $550 \mathrm{~nm}$ (Babior et al., 1970). HRIC was determined according to the guidelines set out by $\mathrm{Yu}$ et al. (2008), who used the Fenton reaction as the hydroxyl radical generation system and rhodamine $\mathrm{B}$ as a spectrophotometric indicator. The plasma ceruloplasmin concentration was determined using the procedure described by Schosinsky et al. (1974), whereby $o$-dianisidine dihydrochloride was used as the substrate. All absorbance levels were measured using a UV-visible spectrophotometer (JASCO Europe srl, Cremella (LC), Italy).

\section{Statistical analysis}

Data were analysed by ANOVA using a completely randomized block design, following the MIXED procedure of SAS v. 9.2 (SAS Institute Inc. Cary, NC, 2008) for a $2 \times 2$ factorial arrangement. The model statement included the effects of dietary treatment (CTR or PP), challenge type (E. coli or saline), and interaction between diet and challenge, as suggested by Liu et al. (2013). The pen represented the experimental unit for growth performance, and individual piglets were the experimental units for the plasma parameters. Differences between treatments were assessed by using the least squares means with a Tukey adjustment. Data with $P \leq 0.10$ were considered to be significant, while those in the $P=0.10-0.20$ range were considered tendencies, as suggested by Jacobs et al. (2013). 


\section{Results}

No effect of PP on growth performance was observed from day 0 to day 21 (data not shown). The inoculation of $E$. coli decreased the G:F ratio from day 21 to day $42(P<0.10$; Table 2$)$. However, dietary PP increased the G:F ratio during three weeks post challenge $(P<0.10)$.

No interaction between challenge and diet was observed in the plasma antioxidative property of piglets (Table 3). E. coli challenge tended to increase the plasma MDA content $(P=0.17)$, reduce plasma SOD $(P=0.18)$ and CAT $(P=0.19)$ activities on day 27; additionally, the challenge tended to decrease plasma T-AOC $(P=0.14)$ and CAT $(P=0.19)$ activities on day 34 . Compared with the
CTR diet, PP supplementation increased plasma GSH-Px activity on day 25 and increased plasma T-AOC activity on day $27(P<0.10)$. Moreover, dietary PP tended to decrease the plasma MDA content on day $25(P=0.14)$ and day $34(P=0.12)$, and increase plasma T-AOC activity on day 34 $(P=0.13)$.

There was no significant interaction between challenge and diet on plasma superoxide anion inhibiting capacity (SAIC), hydroxyl radical inhibiting capacity (HRIC), or ceruloplasmin content (Table 4). E. coli challenge induced a decrease in plasma SAIC and HRIC and an increase in plasma ceruloplasmin content on day $27(P<0.10)$, and tended to reduce plasma SAIC on days 25 $(P=0.19)$ and $34(P=0.16)$. Compared with the

Table 2. Effect of plant polyphenols (PP) supplementation on growth performance of $E$. coli challenged (E. coli) and non-challenged (saline) piglets $^{1}$

\begin{tabular}{|c|c|c|c|c|c|c|c|c|}
\hline \multirow{2}{*}{ Indices } & \multicolumn{2}{|l|}{ Saline } & \multicolumn{2}{|l|}{ E. coli } & \multirow{2}{*}{ SEM } & \multicolumn{3}{|l|}{$P$} \\
\hline & $\overline{C T R}$ & PP & CTR & PP & & $\overline{\mathrm{Ch}}$ & D & $C h \times D$ \\
\hline \multicolumn{9}{|l|}{ Body weight, kg } \\
\hline day 21 & 17.09 & 17.72 & 17.42 & 17.50 & 0.80 & 0.94 & 0.67 & 0.74 \\
\hline day 42 & 31.90 & 32.31 & 31.00 & 31.55 & 1.08 & 0.47 & 0.67 & 0.95 \\
\hline \multicolumn{9}{|l|}{ Day 21 to 42} \\
\hline average daily gain, $\mathrm{g} \cdot \mathrm{d}^{-1}$ & 705 & 695 & 647 & 669 & 32 & 0.23 & 0.86 & 0.62 \\
\hline average daily feed intake, $\mathrm{g} \cdot \mathrm{d}^{-1}$ & 1139 & 1085 & 1117 & 1070 & 45 & 0.69 & 0.29 & 0.94 \\
\hline Gain : Feed & 0.62 & 0.64 & 0.58 & 0.62 & 0.01 & 0.06 & 0.03 & 0.35 \\
\hline
\end{tabular}

${ }^{1} \mathrm{n}=12$ ( 3 pens/treatment). Piglets were weaned at 28 days of age, and half of the piglets were orally challenged with $E$. coli on days 21 and 25 of the trial. Saline - injected saline, E. coli - E. coli inoculation; CTR - basal diet without additive; PP - CTR $+1.0 \mathrm{~g} \cdot \mathrm{kg}^{-1}$ plant polyphenols; Ch - challenge effect (saline vs E. coli); D - diet effect (CTR vs PP); Ch $\times$ D- interaction between challenge and diet

Table 3. Effect of plant polyphenols (PP) supplementation on plasma antioxidative property of $E$. coli challenged (E. coli) and non-challenged (saline) piglets ${ }^{1}$

\begin{tabular}{|c|c|c|c|c|c|c|c|c|}
\hline & \multicolumn{2}{|l|}{ Saline } & \multicolumn{2}{|l|}{ E. coli } & \multirow{2}{*}{ SEM } & \multicolumn{3}{|l|}{$P$} \\
\hline & $\overline{C T R}$ & PP & $\overline{\text { CTR }}$ & PP & & $\overline{C h}$ & D & $C h \times D$ \\
\hline \multicolumn{9}{|l|}{ Day 25} \\
\hline $\mathrm{MDA}, \mathrm{nmol} \cdot \mathrm{ml}^{-1}$ & 3.65 & 1.94 & 3.71 & 2.71 & 0.82 & 0.62 & 0.14 & 0.68 \\
\hline $\mathrm{T}-\mathrm{AOC}, \mathrm{U} \cdot \mathrm{ml}^{-1}$ & 19.92 & 21.63 & 19.19 & 21.15 & 1.94 & 0.76 & 0.37 & 0.95 \\
\hline $\mathrm{SOD}, \mathrm{U} \cdot \mathrm{ml}^{-1}$ & 101 & 103 & 94 & 101 & 4 & 0.30 & 0.31 & 0.59 \\
\hline CAT, U & 13.49 & 21.43 & 11.27 & 14.53 & 6.23 & 0.49 & 0.39 & 0.72 \\
\hline GSH-Px, U & 324 & 461 & 372 & 437 & 38 & 0.77 & 0.03 & 0.37 \\
\hline \multicolumn{9}{|l|}{ Day 27} \\
\hline $\mathrm{MDA}, \mathrm{nmol} \cdot \mathrm{ml}^{-1}$ & 2.73 & 2.62 & 4.56 & 3.23 & 0.82 & 0.17 & 0.41 & 0.48 \\
\hline $\mathrm{T}-\mathrm{AOC}, \mathrm{U} \cdot \mathrm{ml}^{-1}$ & 20.89 & 24.72 & 18.70 & 23.12 & 1.76 & 0.31 & 0.05 & 0.87 \\
\hline $\mathrm{SOD}, \mathrm{U} \cdot \mathrm{ml}^{-1}$ & 99 & 103 & 95 & 97 & 3 & 0.18 & 0.38 & 0.69 \\
\hline CAT, U & 15.17 & 21.60 & 10.88 & 14.42 & 4.00 & 0.19 & 0.25 & 0.73 \\
\hline GSH-Px, U & 478 & 459 & 511 & 476 & 44 & 0.59 & 0.56 & 0.86 \\
\hline \multicolumn{9}{|l|}{ Day 34} \\
\hline $\mathrm{MDA}, \mathrm{nmol} \cdot \mathrm{ml}^{-1}$ & 7.88 & 6.82 & 10.03 & 6.99 & 1.18 & 0.36 & 0.12 & 0.43 \\
\hline $\mathrm{T}-\mathrm{AOC}, \mathrm{U} \cdot \mathrm{ml}^{-1}$ & 24.23 & 30.26 & 19.47 & 24.48 & 3.24 & 0.14 & 0.13 & 0.88 \\
\hline $\mathrm{SOD}, \mathrm{U} \cdot \mathrm{ml}^{-1}$ & 91 & 89 & 88 & 96 & 3 & 0.50 & 0.44 & 0.16 \\
\hline CAT, U & 12.72 & 16.57 & 9.10 & 10.14 & 3.50 & 0.19 & 0.50 & 0.70 \\
\hline GSH-Px, U & 670 & 636 & 591 & 607 & 43 & 0.24 & 0.84 & 0.58 \\
\hline
\end{tabular}

${ }^{1}$ see Table 2; MDA - malondialdehyde, T-AOC - total antioxidant capacity, SOD - superoxide dismutase, CAT - catalase, GSH-Px - glutathione peroxidase; CTR, PP, $\mathrm{CH}, \mathrm{D}$ and $\mathrm{Ch} \times \mathrm{D}$ see Table 2 
Table 4. Effect of plant polyphenols (PP) supplementation on plasma superoxide anion inhibiting capacity (SAIC), hydroxyl radical inhibiting capacity (HRIC) and ceruloplasmin content of $E$. coli challenged (E. coli) and non-challenged (saline) piglets ${ }^{1}$

\begin{tabular}{|c|c|c|c|c|c|c|c|c|}
\hline \multirow{2}{*}{ Indices } & \multicolumn{2}{|l|}{ Saline } & \multicolumn{2}{|l|}{ E. coli } & \multirow{2}{*}{ SEM } & \multicolumn{3}{|l|}{$P$} \\
\hline & $\overline{\mathrm{CTR}}$ & PP & $\overline{C T R}$ & $\mathrm{PP}$ & & $\mathrm{Ch}$ & $\mathrm{D}$ & $C h \times D$ \\
\hline \multicolumn{9}{|l|}{ Day 25} \\
\hline SAIC, $U \cdot I^{-1}$ & 187 & 195 & 185 & 183 & 5 & 0.19 & 0.59 & 0.33 \\
\hline $\mathrm{HRIC}, \mathrm{U} \cdot \mathrm{H}^{-1}$ & 596 & 898 & 657 & 635 & 109 & 0.38 & 0.24 & 0.18 \\
\hline ceruloplasmin, $\mathrm{mg} \cdot \mathrm{l}^{-1}$ & 72.09 & 65.65 & 75.21 & 75.59 & 10.02 & 0.53 & 0.77 & 0.74 \\
\hline \multicolumn{9}{|l|}{ Day 27} \\
\hline SAIC, $\left.U \cdot\right|^{-1}$ & 185 & 191 & 171 & 179 & 4 & 0.03 & 0.09 & 0.50 \\
\hline HRIC, $U \cdot H^{-1}$ & 684 & 684 & 529 & 572 & 64 & 0.07 & 0.75 & 0.76 \\
\hline ceruloplasmin, $\mathrm{mg} \cdot \mathrm{l}^{-1}$ & 62.59 & 51.07 & 75.97 & 66.25 & 5.99 & 0.04 & 0.11 & 0.88 \\
\hline \multicolumn{9}{|l|}{ Day 34} \\
\hline SAIC, $U \cdot \mathrm{F}^{-1}$ & 172 & 182 & 156 & 174 & 8 & 0.16 & 0.11 & 0.65 \\
\hline $\mathrm{HRIC}, \mathrm{U} \cdot \mathrm{H}^{-1}$ & 543 & 697 & 566 & 741 & 66 & 0.63 & 0.04 & 0.88 \\
\hline ceruloplasmin, $\mathrm{mg} \cdot \mathrm{I}^{-1}$ & 85.09 & 75.75 & 71.06 & 72.86 & 9.61 & 0.40 & 0.71 & 0.58 \\
\hline
\end{tabular}

${ }^{1}$ see Table 2; ; CTR, PP, CH, D and Ch $\times$ D see Table 2

CTR group, dietary PP increased plasma SAIC on day 27 and increased plasma HRIC on day 34 $(P<0.10)$. In addition, PP supplementation tended to reduce the plasma ceruloplasmin content on day $27(P=0.11)$ and to increase plasma SAIC on day $34(P=0.11)$ in comparison with the CTR diet.

\section{Discussion}

The objectives of this study were to determine whether a basal diet supplemented with a prepared plant polyphenols (PP) mixture would affect the antioxidant defence system of weaned piglets and to determine whether this supplement could protect piglets against an $E$. coli challenge. In this study, diets containing PP did not affect animal performance during the overall experimental trial, but the PP-fed piglets showed improvements in feed efficiency during the 3 weeks post challenge. These results suggest that PP may improve the stress response of piglets in the post-weaning period, when impaired piglet performance is most likely to occur. Liu et al. (2013) and Bontempo et al. (2014) also reported that piglet growth performance was not affected by plant-extract supplementation. This may be due to several factors, including diet quality, environmental conditions, and herd health status. In addition, the absence of an effect of PP on growth performance in this study may be attributed to the anti-nutritional properties of certain polyphenols (Verhelst et al., 2014) and the inactivation of certain polyphenols by dietary protein (Verhelst et al., 2010). Several studies have shown that weaned piglets experienced diarrhoea and poor growth performance when orally challenged with the enterotoxigenic Escherichia coli (ETEC) strain within a short period following weaning (Liu et al., 2013; Bontempo et al., 2014). Lee et al. (2012) also observed reduced growth performance and diminished faecal consistency, as well as increased inflammatory response, in piglets challenged by ETEC within 14 days following weaning (Lessard et al., 2009). In this study, the injections of E. coli on days 21 and 25 reduced the gain-to-feed ratio during the three weeks post-challenge, which may indicate that $E$. coli challenge (double inoculations in older piglets) can induce negative effects on piglets' growth performance even after their gut microbial environment has matured.

Reactive oxygen species (ROS) are a family of oxygen derivatives, including superoxide, hydroxyl radical, hydrogen peroxide and nitric oxide (Wang et al., 2008). ROS and free radicals are generated and scavenged continuously within an animal's body under normal conditions, with concentrations of ROS and free radicals maintaining homoeostasis. It was reported that antimicrobial-mediated killing of some bacteria appears to involve oxidative stress, as intimated by the accumulation of superoxide anions following exposure to some antimicrobial classes and by reactive oxygen species being associated with ciprofloxacin susceptibility; recent research suggested that hydroxyl radical overproduction may serve as a common path to antimicrobial-mediated cell death (Wang and Zhao, 2009). In this study, the reduced inhibition capacities of superoxide anions and the hydroxyl radical in the challenged piglets may be due to the antimicrobial-mediated cell death caused by the E. coli infection. However, that no challenge effects on other antioxidant capacities were observed suggests that the effects of superoxide and hydrogen peroxide are less acute than those of hydroxyl radicals (Wang and Zhao, 2009). Moreover, susceptibility of pigs to ETEC is to a large part 
a function of expression and preentation of these receptors on the intestinal luminal surface (Francis, 2002), while systemic effects might be limited.

As an acute-phase reactant, ceruloplasmin contributes to inflammatory responses. Increases in plasma ceruloplasmin concentrations commonly accompany pathological states, including infection, trauma, surgery, tissue infarction and advanced cancer (Gabay and Kushner, 1999). Bacterial infection induced an increase in plasma ceruloplasmin concentrations as part of the acute phase response, which is the natural response of the body to extrinsic stimulation. However, the challenge effect on the free radical scavenger or plasma ceruloplasmin concentration was only observed on day 27 , two days following the second challenge, which suggests that the challenge effect may be limited by the age of the animal.

Liu et al. (2013) observed that feeding a plant extract to challenged piglets reduced diarrhoea and inflammation caused by an E. coli challenge. Plant extracts obtained from green tea leaves and pomegranate rinds were also shown to improve gut health and microbial ecology in weanling piglets, thus reducing the severity of an E. coli challenge (Bontempo et al., 2014). In the present study, PP supplementation maintained the feed efficiency of $E$. coli-challenged animals at normal levels during the overall post-challenge period. Many studies have focused on the biological activities of phenolic compounds, which are potential antioxidants and free radical scavengers (Kähkönen et al., 1999; Sugihara et al., 1999; Varga et al., 2001). Polyphenols extracted from apples ( $\mathrm{Lu}$ and Foo, 2000), green teas (Unno et al., 2000), grape seeds (Bagchi et al., 1997) and olive leaves (Lee et al., 2009) have been shown in in vitro studies to be potent scavengers of oxygen free radicals. SOD converts superoxide anions to hydrogen peroxide in a cellular antioxidant reaction, and thereafter, GSH-Px and CAT independently detoxify the produced hydrogen peroxide (Jaeschke, 1995). Plant extracts possess antioxidative characteristics because they can scavenge superoxide anion and hydroxyl radicals (Cao et al., 1993). In the present study, increased GSH-Px and T-AOC activities in PP-fed piglets were observed on day 25 or day 27 , indicating that dietary PP could enhance the capacity to scavenge free radicals and thereby decrease tissue or cell damage due to infection. The present work confirmed that a mixture of plant polyphenols can improve antioxidant defence systems in piglets. Our results are similar to those reported by Rossi et al. (2013), who observed that long-term supplementation with plant extracts tended to increase antioxidant activity in the blood. Enhanced plasma hydroxyl radical inhibiting capacity was seen in PPfed piglets on days 27 and 34, demonstrating that dietary supplementation with PP favourably affected the ability of the animals to reduce the ROS during the challenge. Comparable reduction in plasma ceruloplasmin in piglets fed PP diets on day 6 post infection indicated that dietary PP was most likely beneficial in shortening or overcoming acute phase responses.

\section{Conclusions}

In conclusion, the results of this study suggest that a plant polyphenol mixture consisting of apple, grape seed, green tea and olive leaf polyphenols may improve the systemic antioxidant capacities of weanling piglets under the challenge of $E$. coli.

\section{Acknowledgements}

The authors gratefully appreciate the financial support provided by the UNIAMO project of the University of Milan and the National Key Technology Research \& Development Program (2011BAD26B04) of the China Agriculture Research System Poultry-related Science \& Technology Innovation Team of Peking.

\section{References}

Aebi H., 1984. Catalase in vitro. Methods Enzymol. 105, 121-126

Babior B.M., Kipnes R.S., Curnutte J.J., 1970. Biological defense mechanism. The production by leukocytes of superoxide, a potential bactericide agent. J. Clin. Invest. 52, 791-794

Bagchi D., Garg A., Krohn R.L., Bagchi M., Tran M.X., Stohs S.J., 1997. Oxygen free radical scavenging abilities of vitamins $C$ and $\mathrm{E}$, and a grape seed proanthocyanidin extract in vitro. Res. Commun. Molecul. Pathol. P. 95, 179-189

Benzie I.F., Strain J.J., 1996. The ferric reducing ability of plasma (FRAP) as a measure of 'antioxidant power': the FRAP assay. Anal. Biochem. 239, 70-76

Bontempo V., Jiang X.R., Cheli F., Lo Verso L., Mantovani G., Vitari F., Domeneghini C., Agazzi A., 2014. Administration of a novel plant extract product via drinking water to post-weaning piglets: effects on performance and gut health. Animal 8 , 721-730

Cao Z.F., Chen Z.G., Guo P., Zhang S.M., Lian L.X., Luo L., Hu W.M., 1993. Scavenging effects of ginger on superoxide anion and hydroxyl radical. Zhongguo Zhong Yao Za Zhi (China J. Mat. Med.) 18, 750-751, 764

Fairbrother J.M., Nadeau E., Gyles C.L., 2005. Escherichia coli in postweaning diarrhea in pigs: an update on bacterial types, pathogenesis, and prevention strategies. Anim. Health Res. Rev. 6, 17-39

Fan P., Lou H., 2004. Effects of polyphenols from grape seeds on oxidative damage to cellular DNA. Mol. Cell. Biochem. 267, 67-74 
Francis D.H., 2002. Enterotoxigenic Escherichia coli infection in pigs and its diagnosis. J. Swine Health Prod. 10, 171-175

Gabay C., Kushner I., 1999. Acute-phase proteins and other systemic responses to inflammation. N. Engl. J. Med. 340, 448-454

González R., Ballester I., López-Posadas R., Suárez M.D., Zarzuelo A., Martínez-Augustin O., Sánchez de Medina F., 2011. Effects of flavonoids and other polyphenols on inflammation. Crit. Rev. Food Sci. Nutr. 51, 331-362

Gordon N.C., Wareham D.W., 2010. Antimicrobial activity of the green tea polyphenol (-)-epigallocatechin-3-gallate (EGCG) against clinical isolates of Stenotrophomonas maltophilia. Int. J. Antimicrob. Agents 36, 129-131

Han J., Shuvaev V.V., Muzykantov V.R., 2011. Catalase and SOD conjugated with PECAM antibody distinctly alleviate abnormal endothelial permeability caused by exogenous ROS and vascular endothelial growth factor. J. Pharmacol. Exp. Ther. 338, 82-91

Han Y.H., Moon H.J., You B.R., Kim S.Z., Kim S.H., Park W.H., 2009. The effect of MAPK inhibitors on arsenic trioxide-treated Calu- 6 lung cells in relation to cell death, ROS and GSH levels. Anticancer Res. 29, 3837-3844

Heim K.E., Tagliaferro A.R., Bobilya D.J., 2002. Flavonoid antioxidants: chemistry, metabolism and structure-activity relationships. J. Nutr. Biochem. 13, 572-584

Jacobs B.M., Patience J.F., Lindemann M.D., Stalder K.J., Kerr B.J., 2013. The use of a covariate reduces experimental error in nutrient digestion studies in growing pigs. J. Anim. Sci. 91, 804-810

Jaeschke H., 1995. Mechanisms of oxidant stress-induced acute tissue injury. Proc. Soc. Exp. Biol. Med. 209, 104-111

Kähkönen M.P., Hopia A.I., Vuorela H.J., Rauha J.P., Pihlaja K., Kujala T.S., Heinonen M., 1999. Antioxidant activity of plant extracts containing phenolic compounds. J. Agr. Food Chem. 47, 3954-3962

Lee J.S., Awji E.G., Lee S.J., Tassew D.D., Park Y.B., Park K.S., Kim M.K., Kim B., Park S.C., 2012. Effect of Lactobacillus plantarum CJLP243 on the growth performance and cytokine response of weaning pigs challenged with enterotoxigenic Escherichia coli. J. Anim. Sci. 90, 3709-3717

Lee O.H., Lee B.Y., Lee J., Lee H.B., Son J.Y., Park C.S., Shetty K., Kim Y.C., 2009. Assessment of phenolics-enriched extract and fractions of olive leaves and their antioxidant activities. Bioresource Technol. 100, 6107-6113

Lessard M., Dupuis M., Gagnon N., Nadeau E., Matte J.J., Goulet J., Fairbrother J.M., 2009. Administration of Pediococcus acidilactici or Saccharomyces cerevisiae boulardii modulates development of porcine mucosal immunity and reduces intestinal bacterial translocation after Escherichia coli challenge. J. Anim. Sci. 87, 922-934

Liu Y., Song M., Che T.M., Almeida J.A.S., Lee J.J., Bravo D., Maddox C.W., Pettigrew J.E., 2013. Dietary plant extracts alleviate diarrhea and alter immune responses of weaned pigs experimentally infected with a pathogenic Escherichia coli. J. Anim. Sci. 91, 5294-5306

Lu N., Chen P., Yang Q., Peng Y.Y., 2011. Anti- and pro-oxidant effects of (+)-catechin on hemoglobin-induced protein oxidative damage. Toxicol. Vitro 25, 833-838

Lu Y., Foo Y., 2000. Antioxidant and radical scavenging activities of polyphenols from apple pomace. Food Chem. 68, 81-85
Lykkesfeldt J., Svendsen O., 2007. Oxidants and antioxidants in disease: oxidative stress in farm animals. Vet. J. 173, 502-511

Morinaga N., Iwamaru Y., Yahiro K., Tagashira M., Moss J., Noda M., 2005. Differential activities of plant polyphenols on the binding and internalization of cholera toxin in vero cells. J. Biol. Chem. 280, 23303-23309

NRC, 2012. Nutrient Requirements of Swine. $11^{\text {th }}$ revised Edition. National Academic Press. Washington, DC

Rossi R., Pastorelli G., Corino C., 2013. Application of KRL test to assess total antioxidant activity in pigs: sensitivity to dietary antioxidants. Res. Vet. Sci. 94, 372-377

Schosinsky K.H., Lehman H.P., Beeler M.F., 1974. Measurement of ceruloplasmin from its oxidase activity in serum by use of o-dianisidine dihydrochloride. Clin. Chem. 20, 1556-1563

Sugihara N., Arakawa T., Ohnishi M., Furuno K., 1999. Anti- and prooxidative effects of flavonoids on metal-induced lipid hydroperoxide-dependent lipid peroxidation in cultured hepatocytes loaded with alpha-linolenic acid. Free Radical Biol. Med. 27, 1313-1323

Unno T., Sugimoto A., Kakuda T., 2000. Scavenging effect of tea catechins and their epimers on superoxide anion radicals generated by a hypoxanthine and xanthine oxidase system. J. Sci. Food Agric. 80, 601-606

Valko M., Leibfritz D., Moncol J., Cronin M.T., Mazur M., Telser J., 2007. Free radicals and antioxidants in normal physiological functions and human disease. Int. J. Biochem. Cell Biol. 39, 44-84

Varga Z., Czompa A., Kakuk G., Antus S., 2001. Inhibition of the superoxide anion release and hydrogen peroxide formation in PMNLs by flavonolignans. Phytother. Res. 15, 608-612

Verdonck F., Cox E., van Gog K., Van der Stede Y., Duchateau L., Deprez P., Goddeeris B.M., 2002. Different kinetic of antibody responses following infection of newly weaned pigs with an F4 enterotoxigenic Escherichia coli strain or an F18 verotoxigenic Escherichia coli strain. Vaccine 20, 2995-3004

Verhelst R., Schroyen M., Buys N., Niewold T., 2010. The effects of plant polyphenols on enterotoxigenic Escherichia coli adhesion and toxin binding. Livest. Sci. 133, 101-103

Verhelst R., Schroyen M., Buys N., Niewold T., 2014. Dietary polyphenols reduce diarrhea in enterotoxigenic Escherichia coli (ETEC) infected post-weaning piglets. Livest. Sci. 160, 138-140

Wang X., Zhao X., 2009. Contribution of oxidative damage to antimicrobial lethality. Antimicrob. Agents Chemother. 53, 1395-1402

Wang Y.Z., Xu C.L., An Z.H., Liu J.X., Feng J., 2008. Effect of dietary bovine lactoferrin on performance and antioxidant status of piglets. Anim. Feed Sci. Tech. 140, 326-336

Windisch W., Schedle K., Plitzner C., Kroismayr A., 2008. Use of phytogenic products as feed additives for swine and poultry. J. Anim. Sci. 86, E140-E148

Yu F., Xu D., Lei R., Li N., Li K., 2008. Free-radical scavenging capacity using the fenton reaction with rhodamine $B$ as the spectrophotometric indicator. J. Agr. Food Chem. 56, 730-735

Zhang H.J., Jiang X.R., Mantovani G., Valdez Lumbreras A.E., Comi M., Alborali G., Savoini G., Dell'Orto V., Bontempo V., 2014. Modulation of plasma antioxidant activity in weaned piglets by plant polyphenols. Ital. J. Anim. Sci. 13, 424-430 